\title{
WHAT IS THE EFFECT OF SIZE ON THE USE OF THE EFQM EXCELLENCE MODEL?
}

\section{Introduction}

Organizational excellence can be described as a set of principles and approaches that produce the best overall results and support a sustainable future for organizations (Rusjan, 2005; Kim et al., 2010; EFQM, 2012; Sampaio et al., 2012; Boulter et al., 2013). In order to understand what organizational excellence actually is, closer attention has been paid to Business Excellence Models (BEM). Most existing BEMs have been developed or supported by national bodies as a basis for award programs that disseminate Quality Management (QM) (Dahlgaard et al., 2013). In 2011, there were approximately 100 national BEMs in use (Talwar, 2011), the majority of which were inspired by either the Malcolm Baldrige National Quality Award (MBNQA) or the European Foundation for Quality Management (EFQM)/European Excellence Award criteria. The models underlying these awards encompass the adoption of a collection of best QM practices and the measurement of stakeholder-related performance. Accordingly, BEMs are instruments to assess what an organization does and to identify its achievements, thus the models assume a causal relationship between QM and performance (Kanji, 2002; Bou et al., 2009; Jayamaha et al., 2009, 2011).

A stream of academic research has been examining the adoption and outcomes of BEMs. Several studies (e.g., Hendricks and Singhal, 2001; Corredor and Goñi, 2011; Boulter et al., 2013) have assessed the link between QM practices and performance by focusing on award winners. Considering BEMs as frameworks for QM, the literature has mainly centered on validating the implicit relationships between the operations and results. For example, Bou et al. (2009) and Heras et al. (2012) focused on the EFQM, while He et al. (2011) and Karimi et al. (2014) on the MBNQA, and found positive associations between QM and organizational performance. Their empirical evidence, therefore, suggests that excellence in the management of Enablers-criteria (those that define operations) is associated with excellence in Results.

Since most research has concentrated on the internal structure of the BEMs (the relationship between operations and results), little is known concerning the adoption of the practices embedded in BEMs within distinct organizational contexts. Core to what has been labelled the best practice literature, including studies of BEMs, is the claim of a universal use of management practices (Leseure et al., 2004). Yet, BEMs are not 
prescriptive; organizations may achieve business excellence by excelling in some of the criteria even though they may perform poorly on others (Williams et al. 2006; Gómez et al., 2011; Sampaio et al., 2012). Consequently, the use of practices embedded in the EFQM model and the postulated interrelationships between practices and results may vary with context. Indeed, some authors (e.g., Voss, 2005; Sousa and Voss, 2008) suggest that, since best practices have matured, it is important to investigate the conditions under which these practices work and which of them may be context specific.

A contingency perspective recognizes that successful QM implementations are likely to depend on factors such as size, degree of implementation, type of industry, duration, and environmental characteristics (Hendricks and Singhal, 2001; Zhao et al., 2004; Sila, 2007; Jayaram et al., 2010; Zhang et al., 2012). For example, Hendricks and Singhal (2001) stated that institutional networks impact management practices, and highlighted that inertia tends to be positively associated with firm age and size. In addition, idiosyncratic inter-firm linkages have been considered as determinants of management practices and sources of differential firm performance in other theoretical perspectives, as for example, the "relational view of the firm" (Dyer and Singh, 1998).

In the particular case of the EFQM model, Dahlgaard-Park (2008) and Mohammad et al. (2011) argued for the need to address contingency factors. To the best of our knowledge, the analysis of the joint use of practices embedded in this BEM and how different configurations may emerge according to organizational characteristics has been mainly undertaken regarding sectors, by comparing: private versus public organizations (Eskildsen et al., 2004; Tarí, 2008), high education and other public sectors (Hides et al., 2004), or manufacturing versus services (Gómez et al., 2011). It is noticeable that recently Calvo-Mora et al. (2015) considered the effect of size, but they did not investigate how size might have affected the adoption of the EFQM criteria nor their interrelationships. Hence, how the EFQM model varies with the size of organizations is an open research question. In this context, this article reports an analysis of organizations that have been awarded the "Recognized for Excellence" status in Spain and discriminates two categories: (1) large, (2) small and medium organizations (SMEs). In doing so, it contributes to the scientific assessment of the EFQM Excellence Model that, as highlighted by Williams et al. (2006) and Heras et al. (2012), is important for the legitimization of BEMs. Specifically, it examines differences in the level of adoption of the EFQM criteria and in the relationships that are implicit in the model, which although 
addressed in previous QM studies (e.g., Roca et al., 2006; Sila, 2007) have not been studied in the perspective of the EFQM model. The findings unveil a structure in the use of the EFQM, which accounts for the effect of size and provides insights into the successful adoption of the practices embedded in the model.

The next sections describe the EFQM model and its accreditation scheme, review previous literature concerning the potential effect of size, set the hypotheses to be tested, and describe the methodology used. The empirical study, its findings and implications for different stakeholders are subsequently reported.

\section{Levels of Excellence and the link Enablers-Results}

The EFQM Excellence Model is the most used BEM in Europe and is a comprehensive management model (Williams et al. 2006, Gómez et al., 2011), which is known to reliably reflect the principles of QM (Sousa and Voss, 2002; Bou et al., 2009; Corredor and Goñi, 2011). It was launched in 1991 as a non-prescriptive framework, whose "beauty is that it can be applied to any organization regardless of size, sector or maturity" (http://www.efqm.org/efqm-model/model-criteria). The model is supported by nine criteria, as depicted in Figure 1, where the current version is summarized. Each criterion encompasses sub-criteria that entail best practices, based on which organizations are assessed in their pursuit of excellence. In total, there are 32 sub-criteria.

Figure 1

The Enablers-criteria cover what an organization does, while the Results-criteria cover what an organization achieves. Levels of excellence are established depending on how organizations score in the two sets of criteria. A scheme of recognition was launched by the EFQM, and organizations are encouraged to apply to be assessed. In July 2015, there were 355 valid "Recognized for Excellence" awarded in Spain, which is a country where the EFQM model is widely used (www.efqm.org).

Recognition is awarded by Club Excelencia en Gestión (CEG), which is EFQM's partner in Spain. As Grigg and Mann (2008) or Jayamaha et al. (2009) described, when organizations apply for specific levels of recognition, their management practices are assessed against the model in Figure 1. Points are allocated to each sub-criterion by a panel of assessors using scoring guidelines and evidence of actual performance. All 32 
sub-criteria are evaluated to determine an organization's score, and accreditation is at three levels - 3-star, 4-star and 5-star-, depending on the achieved scores (the minimum thresholds are respectively 300, 400 and 500, and 1000 is the maximum possible score). The accreditation is valid for two years, after which organizations need to apply for reaccreditation.

Considering that BEMs involve multiple paths between criteria (Jayamaha et al., 2011), some studies (e.g., Safari et al., 2012) have focused on the links between isolated Enablers-criteria and some organizational results. Other studies examined whether all Enablers explain excellence in the Results domain. Although the EFQM model does not state clear interrelationships among all individual criteria, causal relationships are implicit, as indicated by the arrows in Figure 1, which were deduced from previous research (e.g., Eskildsen et al., 2004; Bou et al., 2009; Gómez et al., 2011; Heras et al., 2012; Calvo-Mora et al., 2014). For a detailed explanation of each association implicit in Figure 1, one may refer to Heras et al. (2012).

This structural model entails that organizations need an effective Leadership in order to set an appropriate climate to achieve excellence. Given this precondition, stakeholdersrelated performance results from designing products or services considering customer's expectation and having in place effective processes, which are influenced by a strategy coupled with employee-motivational practices, partnerships, and core resources such as data and knowledge-based decision making (Eskildsen et al., 2004; Gómez et al., 2011; Heras et al., 2012). In short, the results achieved by an organization depend on a chain of inductors that have to be made explicit and managed.

\section{Size as a contingency factor in the adoption of the EFQM Model}

\subsection{Contingency analysis of the EFQM criteria}

QM practices should not be addressed from a "one-size fits all" perspective (Zhang et al., 2012), because their adoption may depend on characteristics of the organization. Several studies have, therefore, analyzed how the relationships between QM, or its dimensions, with organizational performance may be contingent (e.g., Ahire and Golhar, 1996; Hendricks and Singhal, 2001; Zhao et al., 2004; Roca et al., 2006; Jayaram et al, 2010; Zhang et al. 2012). As argued in the seminal writings of Dean and Bowen (1994) and Watson and Korukonda (1995), many companies failed to implement QM because of 
using very standardized approaches. The link QM-performance may be contingent on several factors (e.g., sector, firm size and structure, market environment, product orientation, management's perception of quality, program duration, and unionization). Dahlgaard et al. (2013) also hinted at customizations of BEMs.

In the case of the EFQM, some authors (e.g., Gómez et al., 2011; Sampaio et al., 2012) claimed that there may be multiple approaches and ways of adoption. As observed by Williams et al. (2006), an organization can achieve a high level of excellence in some, but not all criteria. Indeed, the choice of practices to use should be aligned to the organization's strategy as well as its needs. Furthermore, with limited resources to be optimized, specific dimensions of QM have to be prioritized. This may be the case in smaller organizations, which often need to be more agile and flexible in order to survive, and generally make use of informal processes and direct communication between line managers and employees. By contrast, large organizations are more likely to emphasize efficiency, greater formalization or higher use of control systems. There is also empirical evidence and theoretical support based on the resource based theory for differences in how size may impact the application of the model in Figure 1. For example, Sturkenboom et al. (2001) and Kumar and Antony (2008) highlighted the need for a customized QM for SMEs, and the EFQM has had separate criteria for SMEs in previous versions.

In an early study of attitudes to self-assessment and quality awards in the UK, Wilkes and Dale (1998) concluded that small and medium enterprises were, in general, aware of the EFQM model, but did not fully understand its benefits. They argued that the pressure of competition and the need to rebuild confidence in the future of the business often meant that SMEs targeted immediate results and were put off by the EFQM model. SMEs needed to be introduced to simplified guidelines to QM before they could use the model and the perception that accreditations were mainly for large organizations had to be changed. Over the years, perceptions might have improved, but still, when the model in Figure 1 is considered, differences in emphases on EFQM criteria between SMEs and large organizations may be expected.

Considering QM, Ghobadian and Gallear $(1996,1997)$ concluded that some features are more compatible with small businesses, while others are independent of size. Similarly, Sun and Cheng (2002) and Lewis et al. (2006) claimed that, in SMEs a greater use of social and soft practices facilitate cultural change and awareness about individual responsibility for quality. Zhao et al.'s (2004) findings supported the view that SMEs on 
average perform well on people management, possibly due to closer relationships and direct negotiations between management and employees. In fact, Calvo-Mora et al. (2014, 2015) concluded that Leadership and People management were important drivers in the adoption of the EFQM model. Yet, literature on human resource management tends to suggest that management practices differ between SMEs and large organizations. Research by Storey et al. (2010) found that the formalization of human resource management in large organizations impinge on employees' perceptions of job autonomy and discretion, which are critical for problem solving and continuous improvement that are part of QM. Moreover, Angell and Corbett (2009) warned that, in small organizations, the lack of resources required for having sufficient evidence of performance against industry benchmarks is a barrier to the achievement of high scores in assessments such as EFQM's. Indeed, Kumar and Antony (2008) concluded that the model is unsuitable, bureaucratic and very time-consuming for SMEs.

Large organizations have been found to emphasize processes management (Lee and Oakes, 1995; Roca et al., 2006) and the structural component of QM, namely formal training and supplier cooperation (Sun and Cheng, 2002). Temtime (2003) and Haar and Spell (2008) concurred that an increase in size means greater resources and benefits from economies of scale, which would facilitate QM implementation. In particular for the achievement of QM awards, Evans et al. (2012) stressed the importance of measurement systems, which together with the use of forecasts are more frequent in larger and formal organizations. Hence, we hypothesize:

H1: The level of adoption of the EFQM criteria differs according to the size of the organization.

Several empirical studies (e.g., Ahire and Golhar, 1996; Taylor and Wright, 2003; Sila, 2007), however, have rejected size as a contingency factor for QM. Overall, they concluded that SMEs can utilize their relative strengths, especially in terms of flexibility, to implement QM elements as effectively as large organizations. In SMEs, flexibility may compensate lack of resources for benchmarking and monitoring. In conclusion, the literature provides mixed evidence concerning the effect of size on QM. Whether or not there are differences in EFQM adoption between SMEs and large organizations is an open research question.

\subsection{Contingency analysis of the relationships among EFQM criteria}


Roca et al. (2006) offered two explanations for why the size of an organization can be a contingency factor in the associations within the EFQM model: (1) the degree of adoption of practices may vary with the size of the organization, as hypothesized above; but also that (2) the intensity of the relationship between QM practices and performance may be affected by size. When the second argument has been examined, the literature also remains inconclusive. For example, Terziovski and Samson's (1999) analysis was supportive, since size moderated the association between QM and performance, in particular, defect rates and warranty costs. When focusing on specific QM dimensions, Gustafsson et al. (2003) found that some practices related to process orientation directly impact customer satisfaction in large organizations, but this effect was not evident in smaller organizations.

Hendricks and Singhal (2001), however, concluded that smaller firms can benefit more from QM. They argued that being smaller may facilitate the understanding of key customers' needs, and organizational learning can be more effective as key practices such as teamwork or empowerment are already present to some extent in smaller firms, thereby lowering their costs of implementing QM. Perhaps not surprising, given mixed findings on moderation, Jayaram et al. (2010) observed that there are relationships which are stronger in large firms and other relationships that are stronger in small firms: "In some instances nimbleness pays off and in other instances scale advantages pay off" (Jayaram et al., 2010, 353).

Moreover, considering the EFQM model, some studies (e.g., Eskildsen et al., 2004; Gómez et al., 2011; Calvo-Mora et al., 2014, 2015) proposed modifications in the theoretical relationships within the model. In spite of variations in the proposals, several alternatives highlight how Leadership and cultural factors are instrumental in improving results. This emphasis reflects a premise in QM, which is that organizations address cultural issues first and then design systems (Abdullah, 2010; Jayaram et al., 2010) by putting in place both social and technical practices ( $\mathrm{Zu}, 2009)$. Indeed, Gómez et al. (2011) put forward an EFQM model, where Leadership is the engine powering the other Enablers-criteria. Other scholars (e.g., Bou et al., 2009, Calvo-Mora et al., 2015) addressed the interrelationships between the Results-criteria in the EFQM model, and proposed a latent factor encompassing the equilibrium in the satisfaction of the stakeholders' needs. Given the different perspectives and findings described above, when 
analyzing the effect of size, variations in the relationships proposed in the EFQM model may also be expected. Consequently, we test the following hypothesis:

$\mathrm{H} 2$ : The size of an organization moderates the associations between criteria in the EFQM model.

\section{Methodology}

\subsection{Data}

A population of 216 Spanish organizations that in March 2013 were "Recognized for Excellence" by Club Excelencia en Gestión (CEG) is considered. Scores obtained in their external independent assessments using the protocol of the EFQM model on all criteria and sub-criteria as well as the final score for each organization are included in the database. Although individual organizations cannot be identified because of a confidentiality agreement with CEG, different sectors of the economy are covered. The majority are schools, universities, healthcare, non-profit, and public administration. Organizations are based in distinct geographical regions in Spain, and their distribution by size is as follow: less than 50 employees: 44 ; between 50 and 249 employees: $87 ; 250$ and more employees: 85 .

\subsection{Measures}

Each criterion was measured by the score provided by CEG, whose assessors allocate values from 0 to 100 , using the results-approach-deployment-assessment and refinement (RADAR) assessment (EFQM, 2012). When considering Enablers sub-criteria, assessors examine the approaches (A) that are adopted, their deployment (D) and how they are assessed and refined over time (AR). When evaluating Results sub-criteria, the focus is on the relevance of results and their performance. Once the sub-criteria scores are allocated for a criterion, their average becomes the score for the criterion. Consequently, in the analyses there are 9 criteria and 32 sub-criteria, as summarized in Table 3 . These assessments are reliable sources of information due to the training and specialization that qualified assessors have (e.g., Jayamaha et al., 2011; Gómez et al., 2011; Heras et al., 2012; Karimi et al., 2014).

Following Gómez et al. (2011), when estimating the baseline structural model (Figure 1), each EFQM criterion was measured by one construct that is equal to the value provided by CEG. This measurement is consistent with previous studies (e.g., Jayamaha et al., 
2009; Heras et al., 2012; Karimi et al., 2014), which used the scores from the external assessment as the measures of criteria in BEMs.

Organization size was operationalized through the number of employees. Following the EU Commission Recommendation (2003/361/EC) and consistent with previous analyses (e.g., Jayaram et al., 2010), a distinction was made between SMEs (those employing less than 250 employees) and large organizations (those with 250 or more employees).

\subsection{Analysis Procedure}

Inspired by Roca et al. (2006) and Sila (2007) analyses of QM practices, a two-stage procedure was undertaken to assess the potential effect of the size.

\section{Testing Hypothesis 1}

First, Chi-square tests of independence were employed to investigate the association between level of recognition and size. Analysis of variance (ANOVA) and t-tests were used to assess differences in EFQM criteria scores. In order to examine the sensitivity of the findings, a Confirmatory Factor Analysis (CFA) with the five Enablers as correlated first-order factors was estimated, and differences between SMEs and large organizations factor-scores were examined. In addition, a disaggregated analysis at sub-criteria level was conducted to compare SMEs and large organizations in more detail.

\section{Testing Hypothesis 2}

In order to examine the relationships implied by the EFQM model, an empirical validation of the baseline structural model (Figure 1) was carried out on the whole sample. Model fit was judged based on Chi-square tests and parameters' standard errors, which were estimated according to Satorra and Bentler (1994) scaled goodness-of-fit test statistics. Given that the baseline model did not fit the data, by inspecting modification indices, alternative theoretical models were examined in the light of previous literature. After identifying an alternative model that fits the population, a multi-sample analysis was used to examine whether the causal relationships were significantly different between SMEs and large organizations. The coefficients in the models were estimated via maximum likelihood using EQS 6.1 (Bentler, 2006).

\section{Results}

\subsection{Preliminary data analysis of the adoption of the EFQM model}


The data were screened for outliers. The sample, which is analyzed, has 214 of the original 216 organizations that constitute the population. It is noteworthy that all organizations in the study have applied to be recognized for excellence, consequently, they must have some understanding of QM principles or at least a level of implementation that they judged to be worthy of accreditation. Table 1 shows descriptive statistics for the Enablers and Results criteria. It indicates potential differences in mean, for these range from 31.10 to 45.55 . Variances are not statistically different, as shown by the standard deviations (S.D.). The correlations between the criteria (the last nine columns of Table 1) are positive and statistically significant at the $1 \%$ level, thus confirming the expected bivariate associations.

Table 1

Figure 2 summarizes the mean scores in each level of excellence. According to an ANOVA, the observed differences in scores between the three groups are statistically significant at the $1 \%$ level. Not surprisingly, the group of 5-stars has the highest means in all sub-criteria, while, the group of 3-stars shows the lowest. All excellence levels score higher in management of processes (SUB 5a). The lowest mean scores relate to Society Results (SUB 8a-8b). Consistent with previous analysis (Blind reference), this plot shows a common pattern in the distribution of scores, thus suggesting a similar interpretation of the model by Spanish organizations that are recognized for excellence.

Figure 2

Table 2 shows the cross-tabulation of level of excellence and size: most of the 39 organizations $(64.1 \%)$ awarded 5-stars recognition are large, whereas most of the 74 organization (67.6\%) awarded 3-stars recognition are SMEs. Given these observed frequencies, there is positive association (Chi-square; 2 d.f.) $=12.90 ; p<0.01$ ): large organizations are more likely to reach a higher level of excellence than SMEs.

Table 2 


\subsection{Contingency analysis of the adoption of EFQM criteria}

Table 3 shows the mean scores in each of the EFQM criteria, significant differences between SMEs and large organizations are highlighted. Accordingly, large organizations have higher scores. However, not all differences are significant, as for example, Leadership and Strategy are similar across SMEs and large companies. In general, large organizations obtained significantly higher scores in People, Partnerships and Resources, Processes, products and services and the Results-criteria, but not in People Results.

Table 3

A Confirmatory Factor Analysis (CFA) of the Enablers-criteria of the EFQM model did not fit the data (BBN-NFI=0.899; RMSEA =0.094). Taking into account the Lagrange multiplier test (LMtest), a new model fitted (BBN-NFI=0.911; RMSEA=0.058). Criterion 5 (Processes, products and services) was divided into two factors, one that accounts for sub-criteria 5a, representing process management, and another that encompasses the correlation of the remaining sub-criteria, which can be interpreted as customer orientation in the design of products. Hence, in this population of recognized for excellence Spanish organizations, six factors represent the Enablers side of the EFQM model. Cronbach's alpha for the multi-item factors are greater than 0.7 , thus implying that the measures are reliable. Significant differences (at $1 \%$ or $5 \%$ significance levels) between SMEs and large organizations were found in People, Partnership and Resources, and the new factor that accounts for sub-criteria $5 \mathrm{~b}$ to $5 \mathrm{e}$. In line with the previous results based on criteria scores, no significant difference was observed in factors representing Leadership and Strategy. Perhaps surprisingly, given previous literature, no differences were found in the new factor denoting process management.

Significant differences in findings were observed when analyzing sub-criteria. First, concerning Leadership (sub-criterion 1e), leaders are more likely to be catalysts of change in large organizations. Second, with respect to Strategy (sub-criterion 2b), large organizations have greater means to develop strategy based on internal performance, because they are likely to have more formal and structured measurement systems. Thirdly, concerning People, no significant differences were found regarding empowerment (sub-criterion $3 \mathrm{c}$ ) and communication (sub-criterion $3 \mathrm{~d}$ ). 
Figure 3

In summary, Hypothesis 1 is partially supported since size was associated with the level of adoption of practices in some, but not in all criteria.

\subsection{The relationships proposed within the EFQM Excellence Model}

Concerning Hypothesis 2, the baseline model in Figure 1 was tested using the sample of 214 organizations. This model did not fit the data (Satorra-Bentler $\chi^{2}=293.86$ (24 d.f.) $[\mathrm{p}$ $=0.00] ; \mathrm{BB}-\mathrm{NNFI}=0.789 ; \mathrm{RMSEA}=0.230$ ). After considering the modification indices, more specifically the LMtest, and the relationships that have been proposed (e.g., Anderson et al., 1994, Nabitz et al., 2001; Jayaram et al., 2010), the model was respecified.

The modified model that followed is shown in Figure 4. It represents Enablers by Leadership and a latent construct that accounts for the correlation between the remaining criteria. In contrast to previous analyses of the EFQM model (e.g., Santos and Alvarez, 2007; Bou et al., 2009) where a single latent construct reflected the enabler side of the model, in Figure 4, two constructs are present. Accordingly, Leadership establishes a climate that is prone to the adoption of other best practices, since it is seen as an engine that guarantees an appropriate system for continuous improvement and monitoring of success (Anderson et al., 1994; Osseo-Asare et al., 2005; He et al., 2011). System Design (SD) captures what Jayaram et al. (2010) call "a socio-technical mix" of practices ranging from people management to process management and resource management. In fact, Manz and Stewart (1997) observed that socio-technical principles are closely aligned with QM practices, and other authors (e.g., Hackman and Wageman, 1995; Lewis et al., 2006; Bou et al., 2009) recognized the dual interrelated emphasis in quality practices (technical and social).

Considering the Results domain, high correlation among criteria was found, thus corroborating previous research by Bou et al. (2009), which identified a latent construct that accounts for the equilibrium in the satisfaction of the stakeholders' interests. A confirmatory factor analysis (CFA) supported a common factor in Results-criteria (BB$\mathrm{NNFI}=0.998 ;$ RMSEA $=0.023$; Cronbach's alpha $=0.882$ ), whose loadings range from 0.744 (Society Results) to 0.879 (Business Results). 
Figure 4

The model in Figure 4 fits the data, as judged by the goodness-of-fit indices (BB-NNFI $=0.981 ;$ RMSEA $=0.07)$ and sample size. Table 4 summarizes the parameter estimates and their significance in the whole sample. It includes the factor loadings of criteria on the latent construct, the structural paths, and the percentage of variance in the results variable that is explained $\left(\mathrm{R}^{2}\right)$. As shown in the second column, all item factor-loadings of the criteria on System Design (SD) are statistically significant, thus indicating that the criteria reflect the latent construct. Moreover, the path coefficients (Structural Effects), linking Leadership to the latent factor (SD) and this to Results, are positive and statistically significant, indicating a high association between Enablers and Results.

Table 4

Following Bentler (2006), a multisample analysis was run constraining factor loadings and structural paths to be equal for both groups of organizations. Goodness-of-fit statistics were then assessed. Only one of the equality constraints (SD-Processes, products and services) can be held, indicating that it is invariant with regard to size. Consequently, the other constraints had to be removed, and there is an effect of size. The output for the resulting model is summarized in columns 4 to 7 of Table 4 (Multisample Analysis). This model fits the data, according to its p-value and fit indices shown at the bottom of the table (Multisample Global Fit). All factor loadings and structural coefficients are positive and significant (SMEs, Large). In addition, the coefficients of determination $\left(\mathrm{R}^{2}\right)$ of the corresponding regressions are mostly greater than 0.7 , indicating that the model explains a substantial amount of the variance in the data.

When the parameter estimates in Table 4 are compared, only one estimate (Processes, products and services) is not statistically different between SMEs and large organizations. System Design differs between the two groups, because loadings are higher for large organizations. Considering the paths towards Results, parameter estimates are also higher for large organizations. In consequence, there is an effect of size that seems to favor large organizations.

\section{Discussion}




\subsection{On the hypotheses tested}

\section{Hypothesis 1: A contingency perspective on the adoption of the EFQM model}

This paper contributes to the debate on the universal adoption versus the contingent use of best practices in QM. Large organizations were found to exhibit a higher adoption of best practices within the EFQM model in some criteria, but not in all, thus corroborating early articles by Ghobadian and Gallear $(1996,1997)$. In addition, some elements in the EFQM model appear universally applicable namely: Leadership (except for the role of leader as agent of change); the consideration of stakeholders in Strategy formation and deployment; and specific high involvement practices, such as empowerment (3c) and communication (3d) that, according to Gooderham et al. (2008), foster collaboration within the organization. Similarly, process design and process management practices (5a), contrary to some previous conclusions (Roca et al., 2006), do not differ regarding size. The apparent universal adoption of these practices by organizations that are recognized for excellence is not surprising, since the basic principles of QM imply that empowered employees, well designed and managed processes, and communication are critical for problem-solving and team-working.

By contrast, the uses of several practices were found to be contingent on size. Most noticeably, large organizations and SMEs differed in how they train and reward people; manage their partnerships and resources, and design, market, deliver and customize products and services. Concerning People, the findings are consistent with previous research that show training and rewards systems to be more common in large organizations (e.g., Ghobadian and Gallear, 1996, 1997; Sun and Cheng, 2002). Within the Enablers, it also appears that more technical practices are more likely to be customized by organizations. In fact, Gómez et al. (2011) found differences in the adoption of the more technical Enablers, when examining industrial and service companies. Organizations may be adapting some QM practices to their day to day context and constraints, as observed by Ghobadian and Gallear (1996, 1997). Moreover, limited resources may prevent SMEs from having sophisticated performance measurement systems (Angell and Corbett, 2009) and moving towards fact-based management, as highlighted by the observed differences in sub-criterion $2 b$.

Further analysis of differences between small and medium organizations at the criteria level reinforces the contingency effect of size. Small and medium organizations differ in 
their management of Partnerships, resources, Processes, products and services and in the results they obtain regarding society. All in all, there are suggestions that limited resources impact the ability to obtain high scores in certain criteria in the EFQM model.

When comparing to previous studies of the adoption of the EFQM, the potential effect of size observed in the present study do not fully support Calvo-Mora et al.'s (2015) conclusions that large organizations are stronger in managing the elements in the EFQM model. Differences in findings could stem from the fact that the authors focused on three factors that encompassed Enablers-criteria, rather than examining sub-criteria. In which case, disaggregation may impact findings.

Hypothesis 2: A contingency perspective on the relationships in the EFQM model

Concerning the relationships in the EFQM model, the present study supports previous conclusions (e.g., Terziovski and Samson, 1999; Sun and Cheng, 2002; Roca et al., 2006) that size is a moderator in the association between Enablers and Results. It appears that greater access to resources, which is generally associated with large organizations (Haar and Spell, 2008; Abdullah, 2010), plays an important part in linking the use of best practices to the achievement of results. By contrast, there is no support for Hendricks and Singhal's (2001) and Jayaram et al.'s (2010) conclusions that the nimbleness associated with small firms would link QM practices to results, nor for Ahire and Golhar's (1996) and Sila's (2007) findings that size is neither linked with QM adoption nor moderates the association with performance.

The use of perceptions or subjective measures of QM practices in previous studies may explain divergences in findings. Moreover, as noted by Sturkenboom et al. (2001) and Sun and Cheng (2002), the definition of SMEs varies widely, and may have led to conflicting findings. For instance, Sila (2007) defined SMEs as having up to 500 employees, while here the threshold is 250 employees. Finally, differences may be due to variations in the conceptualization and measurement of performance, for example, Hendricks and Singhal (2001) focused on operating income and sales, while the EFQM definition of performance implies a wider range of results and stakeholders.

\subsection{On the elements of the EFQM model}

\section{The EFQM model in practice}


A main contribution of this study is a call for the revision of the relationships embedded in the EFQM model. As shown by Gómez et al. (2011) and Heras et al. (2012), the model does not work as expected, as some of the implicit relationships are not empirically supported. The present findings extend previous analyses by suggesting a network of relationships, which is consistent with Jayaram et al.'s (2010: 352) QM model, where “an early emphasis on culture variables does enhance the design of quality systems, specifically a mix of socio-technical tools, which in turn positively affects QM outcomes". Hence, a general structure in the EFQM model was here identified, where size is likely to determine the way the QM system is designed. This study therefore reinforces the need for a comprehensive and integrated QM (Hackman and Wageman, 1995; Bou et al., 2009; Zu, 2009; Calvo-Mora et al., 2015). It does not support previous observations (e.g., Laohavichien et al., 2011) that core (hard) QM practices mediate the relationship between infrastructure (soft) QM practices and results. In all, according to this population of Spanish organizations, SMEs do not prioritize People nor large organizations emphasize Processes, i.e., for organizations in the path to excellence, the social is as important as the technical as both form part of a management system.

The potential effect of size on the role of Leadership

Given the model identified and in line with Abdullah's (2010) conclusions, this study argues for a facilitating role of Leadership in creating the necessary breeding climate for the design of a system of best practices and high performance. It also highlights how Leadership may play different roles in organizations of different sizes. Leaders are managers of change in large organizations. For example, Vaccaro et al (2012) observed that the stronger role of transformational leaders in larger organizations compensated for institutional complexity. In SMEs, a more people-oriented, less hierarchical and flexible approach (Ghobadian \& Gallear, 1996, 1997; Assarlind \& Gremyr, 2014) facilitates the communication of policies and strategies, and therefore the role of leaders in change management is less paramount. This observation may contradict a common perception that small organizations rely on their owner to implement change. It is possible that role of Leadership as catalyst of change can be replaced or diluted by empowered and autonomous teams that can influence the process needed to the successful adoption of the EFQM model. It could also be that time is more crucial for smaller organizations and thus all levels in the organization need to be equally actively involved in change management. 
The present study also has implications for how SMEs and large organizations address high performance work practices in the context of the EFQM model. The findings suggest that (Spanish) SMEs may have limited resources (Ghobadian and Gallear, 1996; Jayaram et al., 2010) to invest in the skill and motivational practices of high performance work systems (Huselid, 1995), which are implicit in BEMs. Moreover, the incidence of human resource plans supporting the organization's strategy was observed to be higher in large organizations. However, no differences were found in other high involvement practices (e.g., empowerment and communication). Hence, in smaller organizations, it may even be that direct communication becomes a substitute for training due to informality, fewer layers of management or barriers between departments. As stressed by Allen et al. (2013), smaller organizations emphasize commitment-based HR practices. Finally, People Results were found to be independent of size. That is, although SMEs address human resource management differently from large organizations, in Spain, the practices that they use are equally effective.

\subsection{Practical implications for managers}

The model in Figure 4 imply that Leadership is critical to the development of a systemic approach that balances social and technical best practices, as concluded in previous analyses of the EFQM model (e.g., Bou et al., 2009, Calvo-Mora et al., 2014, 2015). Extending Jayaram et al. (2010) conclusions, when using the EFQM model for benchmarking, managers should consider benchmarks that share similar contextual factors. Otherwise, they would emulate best practices that may not work as well in their context.

As a whole the findings of this research support Gustafsson et al.'s (2003) observations that the QM strategy must change when an organization grows. In doing so, they question the current version of the EFQM model as a framework that can be applied to any organization, regardless of size. EFQM could therefore reconsider the development of a separate set of criteria for SMEs that reflect the size of organizations. In all, promoters of BEMs can benefit from this research in designing or improving their models.

\subsection{Limitations and future research}

This study has focused on the possible effect that size may have on how organizations interpret the EFQM model. Given its findings, an avenue for future research is an investigation of how SMEs can design and improve performance measurement systems, 
or how standard systems and software can be adapted to resources. It may be that lighter versions of software could facilitate fact-based management and the information sharing that is critical in managing partnerships. Furthermore, the different effects of size on soft and hard elements of QM suggest a need for investigating other contingency factors in the adoption of social and technical practices within the EFQM model.

In this sense, there are other contextual factors to be considered, such as the length of time the organization is committed to a QM initiative, sector, organization strategy, structure or environmental features. The data available for this study does not enable a broader analysis of contextual factors. Although the database only enables the comparison of a few sectors, an attempt was made to identify sectorial differences in each group of organizations (SMEs and large). In the main, there were no significant differences in criteria across sectors, thus supporting Calvo-Mora et al.'s (2015) aggregated sectorial analysis. The only difference observed was in relation to criterion 8 (Society Results), since large organizations in the health sector perform better than those in the education sector. Nonetheless, this observation should be interpreted with care because of the very small sample sizes. In this line of research, analyses of large samples that include all sectors in the economy are needed, so that the pairwise observations made in the literature (e.g., Tarí, 2008; Gómez et al., 2011) can be finally tested in more representative settings. Furthermore, the evolution of organizations from their early use of the EFQM to their current adoption cannot be captured by a static study. Future research should aim to examine longitudinal data covering a sequence of applications to the recognition scheme, which would allow for the identification of the path(s) that are followed by organizations in their road towards excellence.

\section{Conclusion}

This study has analyzed organizational size as a contingency factor in interpreting the EFQM Excellence Model. Its first goal was to investigate differences in the use of best practices embedded in the model and in the results attained. The second goal was to examine how size may moderate the relationships between criteria. The findings suggest the existence of a subset of high involvement and process management practices that are more universally applicable, but also that other practices may be customized or are more dependent in local resources. This hybrid approach to the model can be a promising way 
to reconcile the universal adoption and the adaptation of best practices to organizational context.

The findings reinforce the EFQM model as a system and the role of Leadership as a key to develop a systemic approach that balances social and technical best practices to improve results. Criteria should be integrated, so that they can perform effectively. Nevertheless, the findings suggest that an equivalent effort in improving Leadership and systems design may lead to greater effects in large organizations.

In conclusion, the present study contributes to the contingency theory on BEMs. It provides new insights for the successful adoption of management practices embedded in the EFQM model, as well as for assessors and bodies that promote the EFQM model, as there seems to be a case for considering the potential effects of size. 


\section{References}

Abdullah, A. (2010), "Measuring TQM implementation: a case study of Malaysian SMEs", Measuring Business Excellence, Vol. 14, No 3, pp. 3-15.

Ahire, S. L., \& Golhar, D. Y. (1996), "Quality management in large vs small firms", Journal of Small Business Management, Vol. 34, No. 2, pp. 1-13.

Allen, M. R., Ericksen, J., \& Collins, C. J. (2013), "Human resource management, employee exchange relationships, and performance in small businesses", Human Resource Management, Vol. 52, No. 2, pp. 153-173.

Anderson, J. C., Rungtusanatham, M., \& Schroeder, R. G. (1994), “A theory of quality management underlying the Deming management method", Academy of Management Review, Vol. 19, No. 3, pp. 472-509.

Angell, L. C., \& Corbett, L. M. (2009), "The quest for business excellence: evidence from New Zealand's award winners", International Journal of Operations \& Production Management, Vol. 29, No. 2, pp. 170-199.

Assarlind, M., \& Gremyr, I. (2014), "Critical factors for quality management initiatives in small-and medium-sized enterprises", Total Quality Management \& Business Excellence, Vol. 25, No. 3-4, pp. 397-411.

Bentler, P. M. (2006), EQS structural equations program manual, Multivariate Software, Inc., Encino, CA.

Bou, J. C., Escrig, A. B., Roca, V., \& Beltrán, I. (2009), “An empirical assessment of the EFQM Excellence Model: Evaluation as a TQM framework relative to the MBNQA Model", Journal of Operations Management, Vol. 27, No. 1, pp. 1-22.

Boulter, L., Bendell, T., \& Dahlgaard, J. (2013), "Total quality beyond North America: A comparative analysis of the performance of European Excellence Award winners", International Journal of Operations \& Production Management, Vol. 33, No. 2, pp. 197-215.

Calvo-Mora, A., Picón, A., Ruiz, C., \& Cauzo, L. (2014), “The relationships between soft-hard TQM factors and key business results", International Journal of Operations \& Production Management, Vol. 34, No. 1, pp. 115-143.

Calvo-Mora, A., Picón-Berjoyo, A., Ruiz-Moreno, C., \& Cauzo-Bottala, L. (2015), "Contextual and mediation analysis between TQM critical factors and organisational results in the EFQM Excellence Model framework", International Journal of Production Research, Vol. 53, No. 7, pp. 2186-2201.

Commission of the European Communities (2003), Commission recommendation of 6 May 2003 concerning the definition of micro, small and medium-sized enterprises, Official Journal of the European Union, L 124, 20/05/2003, pp. 36-41.

Corredor, P., \& Goñi, S. (2011), "TQM and performance: Is the relationship so obvious?" Journal of Business Research, Vol. 64, pp. 830-838.

Dahlgaard, J. J., Chen, C. K., Jang, J. Y., Banegas, L. A., \& Dahlgaard-Park, S. M. (2013), "Business excellence models: limitations, reflections and further development", Total Quality Management \& Business Excellence, Vol. 24, No. 5-6, pp. 519-538.

Dahlgaard-Park, S. M. (2008), "Reviewing the European excellence model from a management control view", The TQM Journal, Vol. 20, No. 2, pp.98-119. 
Dean, J. W. \& Bowen, D. E. (1994), "Management theory and total quality: improving research and practice through theory development", Academy of Management Review, Vol. 19, No. 3, pp. 392-418.

Dyer, J. H., \& Singh, H. (1998), “The relational view: Cooperative strategy and sources of interorganizational competitive advantage", Academy of Management Review, Vol. 23, No. 4, pp. 660-679.

Eskildsen, J. K., Kristensen, K., \& Juhl, H. J. (2004), "Private versus public sector excellence", The TQM Magazine, Vol. 16, No. 1, pp.50-56.

European Foundation for Quality Management (EFQM) (2012), EFQM Model for Business Excellence, EFQM, Brussels.

Evans, J. R., Ford, M. W., Masterson, S. S. \& Hertz, H. S. (2012), "Beyond performance excellence: research insights from Baldrige recipient feedback", Total Quality Management \& Business Excellence, Vol. 23, No. 5-6, pp. 89-506.

Ghobadian, A., \& Gallear, D. N. (1996), "Total quality management in SMEs", Omega, Vol. 24, No. 1, pp. 83-106.

Ghobadian, A., \& Gallear, D. N. (1997), “TQM and organization size”, International Journal of Operations \& Production Management, Vol. 17, No. 2, pp. 121-163.

Gómez, J., Martínez, M., \& Martínez, A. R. (2011), “A critical evaluation of the EFQM model", International Journal of Quality \& Reliability Management, Vol. 28, No. 5, pp. 484-502.

Gooderham, P., Parry, E., \& Ringdal, K. (2008), “The impact of bundles of strategic human resource management practices on the performance of European firms", The International Journal of Human Resource Management, Vol. 19, No. 11, pp. 20412056.

Grigg, N., \& Mann, R. (2008), "Rewarding excellence: an international study into business excellence award processes", Quality Management Journal, Vol. 15, No. 3, pp. 26-40.

Gustafsson, A., Nilsson, L., \& Johnson, M. D. (2003), "The role of quality practices in service organizations", International Journal of Service Industry Management, Vol. 14, No. 2, pp. 232-244.

Haar, J. M., \& Spell, C. S. (2008), "Predicting total quality management adoption in New Zealand: The moderating effect of organisational size", Journal of Enterprise Information Management, Vol. 21, No.2, pp. 162-178.

Hackman, J. R., \& Wageman, R. (1995), "Total quality management: empirical, conceptual, and practical issues", Administrative Science Quarterly, Vol. 40, pp. 309342 .

He, Z., Hill, J., Wang, P., \& Yue, G. (2011), "Validation of the theoretical model underlying the Baldrige criteria: Evidence from China", Total Quality Management, Vol. 22, No. 2, pp. 243-263.

Hendricks, K. B., \& Singhal, V. R. (2001), "Firm characteristics, total quality management, and financial performance", Journal of Operations Management, Vol. 19, pp. 269-285. 
Heras, I., Marimon, F., \& Casadesús, M. (2012), "An empirical study of the relationships within the categories of the EFQM model", Total Quality Management \& Business Excellence, Vol. 23, No. 5-6, pp. 523-540.

Hides, M. T., Davies, J., \& Jackson, S. (2004), "Implementation of EFQM excellence model self-assessment in the UK higher education sector-lessons learned from other sectors", The TQM Magazine, Vol. 16, No. 3, pp. 194-201.

Huselid, M. A. (1995), "The impact of human resource management practices on turnover, productivity, and corporate financial performance", Academy of Management Journal, Vol. 38, No. 3, pp. 635-672.

Jayamaha, N., Grigg, N., \& Mann, R. (2009), "A study of the validity of three major business excellence models in the Asia Pacific region", Total Quality Management, Vol. 20, No. 11, pp. 1213-1227.

Jayamaha, N., Grigg, N., \& Mann, R. (2011), "Empirical analysis of the Baldrige criteria as both an organizational performance measure and a theoretical model", Measuring Business Excellence, Vol. 15, No. 1, pp. 20-33.

Jayaram, J., Ahire, S. L., \& Dreyfus, P. (2010), "Contingency relationships of firm size, TQM duration, unionization, and industry context on TQM implementation-A focus on total effects", Journal of Operations Management, Vol. 28, No. 4, pp. 345-356.

Kanji, G. K. (2002), "Performance measurement system”, Total Quality Management, Vol. 13, No. 5, pp. 715-28.

Karimi, A., Safari, H., Hashemi, S. H., \& Kalantar, P. (2014), "A study of the Baldrige Award framework using the applicant scoring data", Total Quality Management \& Business Excellence, Vol. 25, No. 5-6, pp. 461-477.

Kim, D. Y., Kumar, V., \& Murphy, S. A. (2010), "European foundation for quality management business excellence model: an integrative review and research agenda", International Journal of Quality \& Reliability Management, Vol. 27, No. 6, pp. 684-701.

Kumar, M., \& Antony, J. (2008), "Comparing the quality management practices in UK SMEs”, Industrial Management \& Data Systems, Vol. 108, No. 9, pp. 1153-1166.

Laohavichien, T., Fredendall, L. D. \& Cantrell, R. S. (2011),"Leadership and quality management practices in Thailand", International Journal of Operations \& Production Management, Vol. 31, No. 10, pp. 1048 - 1070.

Lee, G. L. \& Oakes, I. (1995), “The 'pros' and ‘cons' of Total Quality Management for smaller companies in manufacturing: some experiences down the supply chain", Total Quality Management, Vol. 6, pp. 413-426.

Leseure, M. J., Bauer, J., Birdi, K., Neely, A., \& Denyer, D. (2004), "Adoption of promising practices: a systematic review of the evidence", International Journal of Management Reviews, Vol. 5, No. 3-4, pp. 169-190.

Lewis, W. G., Pun, K. F., \& Lalla, T. R. M. (2006), "Exploring soft versus hard factors for TQM implementation in small and medium-sized enterprises", International Journal of Productivity and Performance Management, Vol. 55, No. 7, pp. 539-554.

Manz, C. C., \& Stewart, G. L. (1997), "Attaining flexible stability by integrating total quality management and socio-technical systems theory", Organization Science, Vol. 8, No. 1, pp. 59-70. 
Mohammad, M., Mann, R., Grigg, N., \& Wagner, J. P. (2011), "Business Excellence Model: An overarching framework for managing and aligning multiple organisational improvement initiatives", Total Quality Management \& Business Excellence, Vol. 22, No. 11, pp. 1213-1236.

Nabitz, U., Severens, P., Van Den Brink, W., \& Jansen, P. (2001), "Improving the EFQM Model: An empirical study on model development and theory building using concept mapping", Total Quality Management, Vol. 12, No. 1, pp. 69-81.

Osseo-Asare, A. E., Longbottom, D. \& Murphy, W. D. (2005),'Leadership best practices for sustaining quality in UK higher education from the perspective of the EFQM Excellence Model", Quality Assurance in Education, Vol. 13, No. 2, pp. 148 - 170

Roca, V., Escrig, A. B., Bou, J. C., \& Beltrán, I. (2006), “A systemic and contingent view of the basic elements of quality management", Total Quality Management and Business Excellence, Vol. 17, No. 9, pp. 1111-1127.

Rusjan, B. (2005), "Usefulness of the EFQM Excellence model: theoretical explanation of some conceptual and methodological issues", Total Quality Management, Vol. 16, No. 6, pp. 363-380.

Safari, H., Abdollahi, B., \& Ghasemi, R. (2012), "Canonical correlation analysis between people criterion and people results criterion in EFQM model", Total Quality Management \& Business Excellence, Vol. 23, No. 5-6, pp. 541-555.

Sampaio, P., Saraiva, P., \& Monteiro, A. (2012), “A comparison and usage overview of business excellence models”, The TQM Journal, Vol. 24, No. 2, pp. 181-200.

Santos, M. L., \& Álvarez, L. I. (2007), "Innovativeness and organizational innovation in total quality oriented firms: The moderating role of market turbulence", Technovation, Vol. 27, No. 9, pp. 514-532.

Satorra, A. \& Bentler, P. M. (1994), "Corrections to test statistics and standard errors in covariance structure analysis", in von Eye, A., Clogg, C. C. (Eds.), Latent Variables Analysis: Applications for Developmental Research, Sage, Thousand Oaks, CA, pp. 399-419.

Sila, I. (2007), "Examining the effects of contextual factors on TQM and performance through the lens of organizational theories: An empirical study", Journal of Operations Management, Vol. 25, pp. 83-109.

Sousa, R., \& Voss, C. A. (2002), "Quality management re-visited: a reflective review and agenda for future research", Journal of Operations Management, Vol. 20, pp. 91-109.

Sousa, R., \& Voss, C. A. (2008), "Contingency research in operations management practices", Journal of Operations Management, Vol. 26, No. 6, pp. 697-713.

Storey, D. J., Saridakis, G., Sen-Gupta, S., Edwards, P. K. \& Blackburn, R. A. (2010), "Linking HR formality with employee job quality: the role of firm and workplace size”. Human Resource Management, Vol. 49, No. 2, pp. 305-329.

Sturkenboom, J., Van Der Wiele, T., \& Brown, A. (2001), “An action-oriented approach to quality management self-assessment in small and medium-sized enterprises", Total Quality Management, Vol. 12, No. 2, pp. 231-246.

Sun, H., \& Cheng, T. K. (2002). "Comparing reasons, practices and effects of ISO 9000 certification and TQM implementation in Norwegian SMEs and large firms". International Small Business Journal, Vol. 20, No. 4, pp. 421-442. 
Talwar, B. (2011), "Business excellence models and the path ahead", The TQM Journal, Vol. 23, No. 1, pp. 21-35.

Tarí, J. (2008), "Self-assessment exercise: a comparison between a private sector organization and higher education institutions", International Journal of Production Economics, Vol. 114, pp. 105-18.

Taylor, W. A., \& Wright, G. H. (2003), “A longitudinal study of TQM implementation: factors influencing success and failure", Omega, Vol. 31, No. 2, pp. 97-111.

Temtime, Z. T. (2003),' The moderating impacts of business planning and firm size on total quality management practices", The TQM Magazine, Vol. 15, No. 1, pp. 52-60.

Terziovski, M. \& Samson, D. (1999), "The link between total quality management practice and organisational performance", International Journal of Quality \& Reliability Management, Vol. 16, No. 3, pp. 226-237.

Vaccaro, I. G., Jansen, J. J., Van Den Bosch, F. A., \& Volberda, H. W. (2012), "Management innovation and leadership: The moderating role of organizational size". Journal of Management Studies, Vol. 49, No.1, pp. 28-51.

Voss, C. A. (2005), "Paradigms of manufacturing strategy re-visited", International Journal of Operations \& Production Management, Vol. 25, No. 12, pp. 1223-1227.

Watson, J. G., Korukonda, A. R. (1995), "The Total Quality Management Jungle: a Dialectical Analysis", International Journal of Quality \& Reliability Management, Vol. 12, No. 9, pp. 100-109.

Wilkes N, \& Dale, B. (1998), "Attitudes to self-assessment and quality awards: A study in small and medium-sized companies", Total Quality Management, Vol. 9, No. 8, pp. 731-739.

Williams, R., Bertsch, B., Van der Wiele, A., Van Iwaarden, J., \& Dale, B. (2006), "SelfAssessment against Business Excellence Models: A Critique and Perspective", Total Quality Management and Business Excellence, Vol. 17, No. 10, pp. 1287-1300.

Zhang, D., Linderman, K., \& Schroeder, R. G. (2012), " The moderating role of contextual factors on quality management practices", Journal of Operations Management, Vol. 30, No.1, pp. 12-23.

Zhao, X., Yeung, A. C., \& Lee, T. S. (2004), "Quality management and organizational context in selected service industries of China", Journal of Operations Management, Vol. 22, No. 6, pp. 575-587.

$\mathrm{Zu}, \mathrm{X}$. (2009), "Infrastructure and core quality management practices: how do they affect quality?" International Journal of Quality \& Reliability Management, Vol. 26, No. 2 , pp. 129-149. 
Figure 1. The EFQM Excellence Model

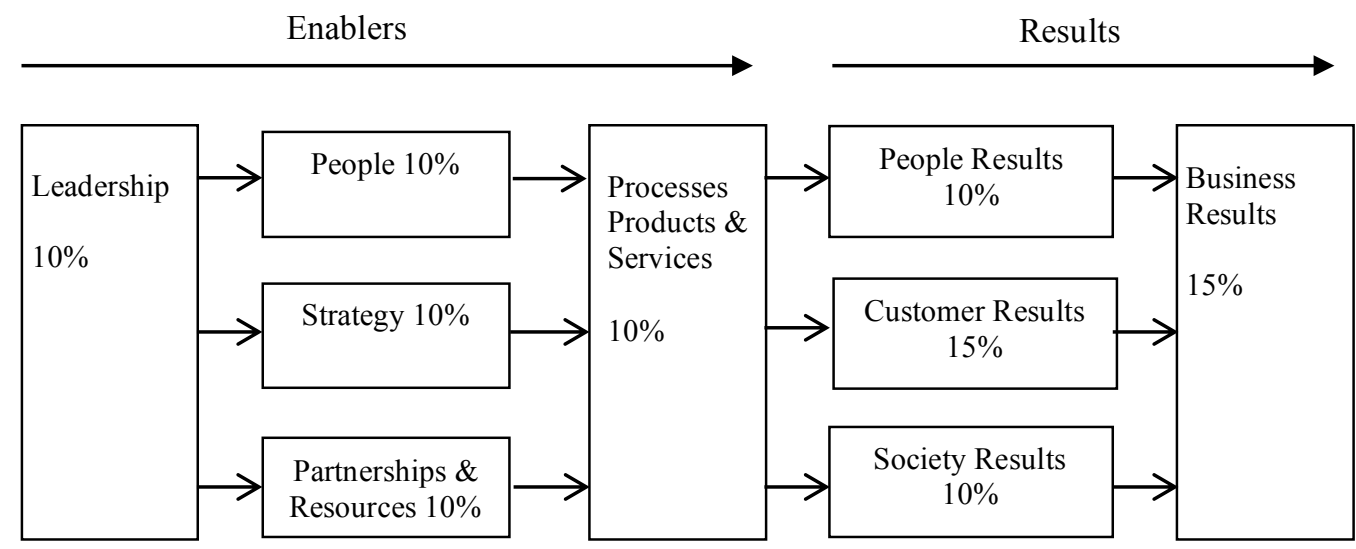

Learning, Creativity and Innovation

Source: adapted from EFQM (2012)

Figure 2. Mean sub-criteria scores by excellence level

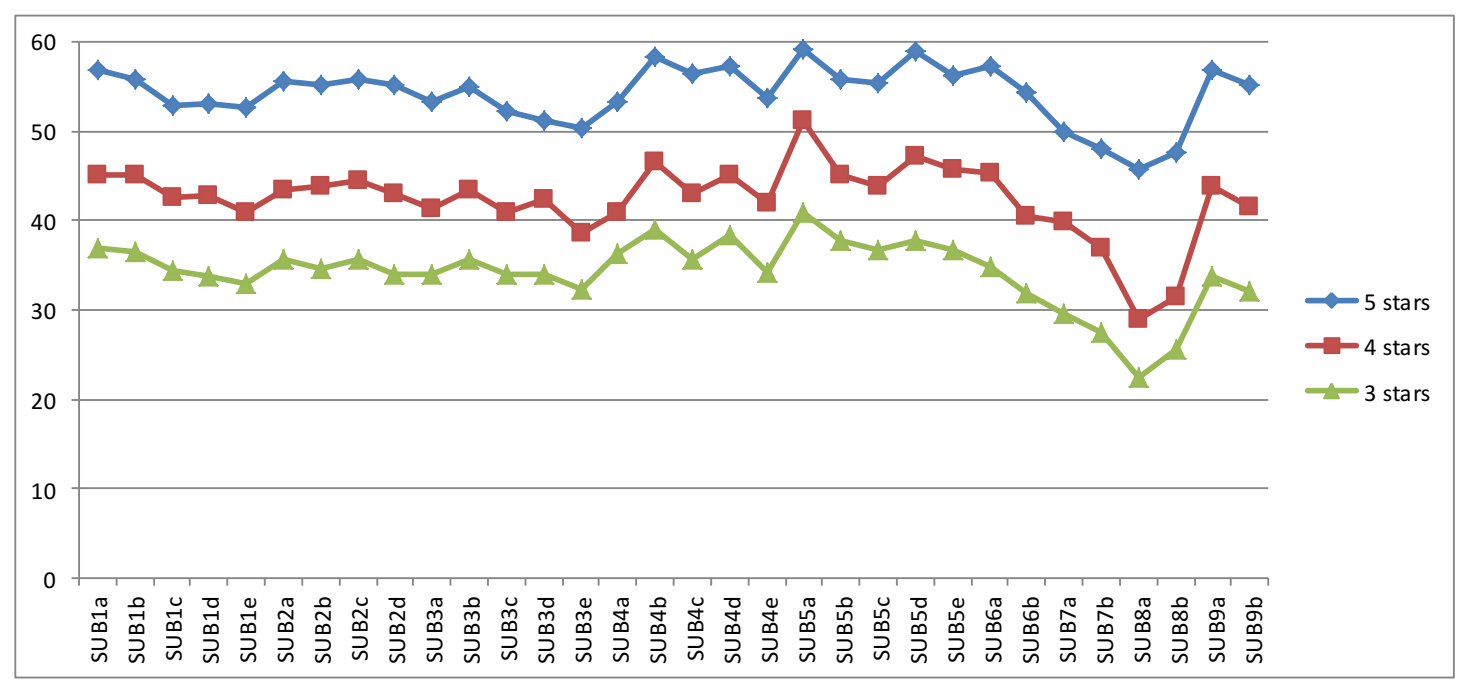


Figure 3. Mean sub-criteria scores by size

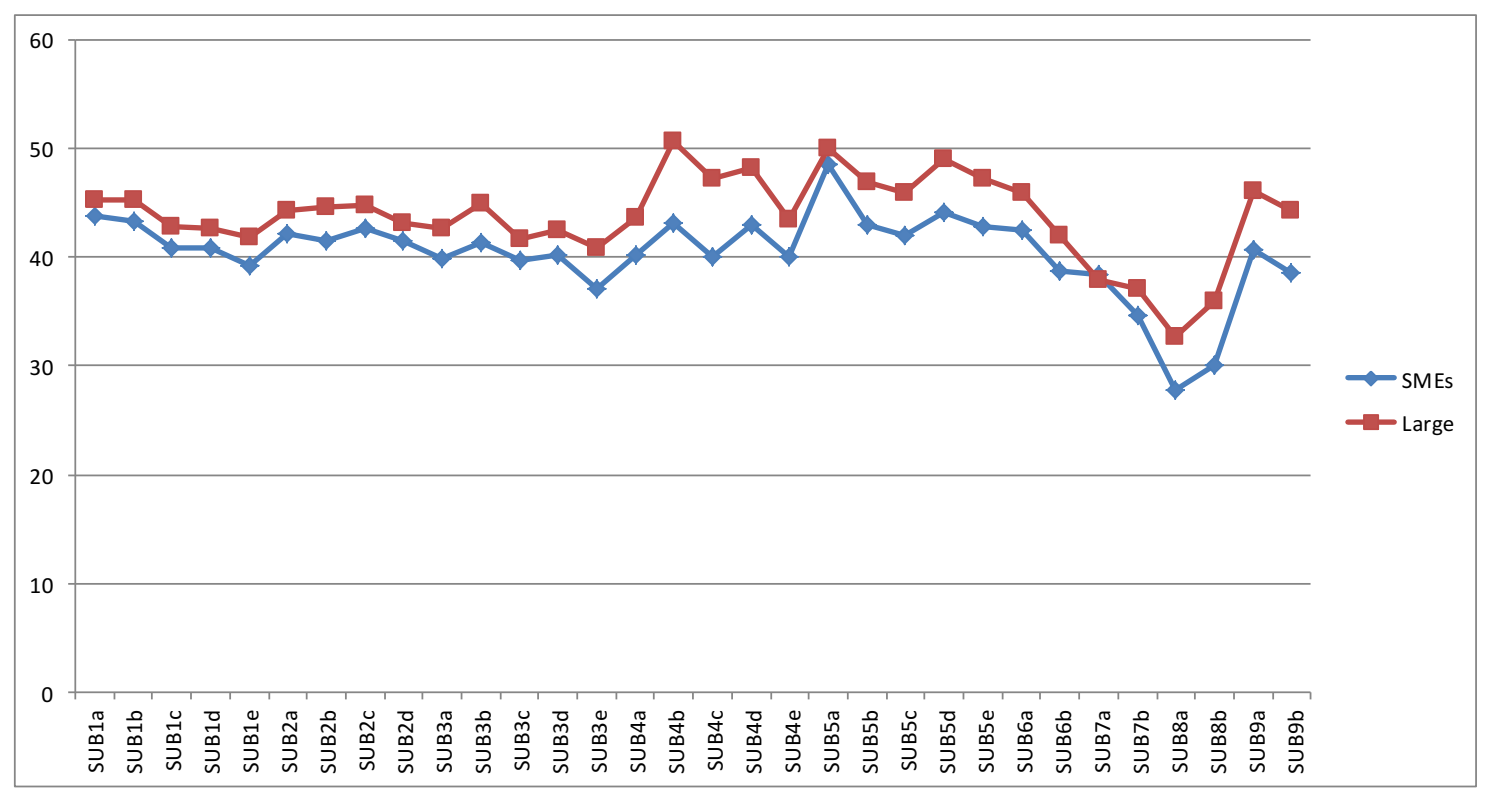

Figure 4: Modified structural model for the whole sample

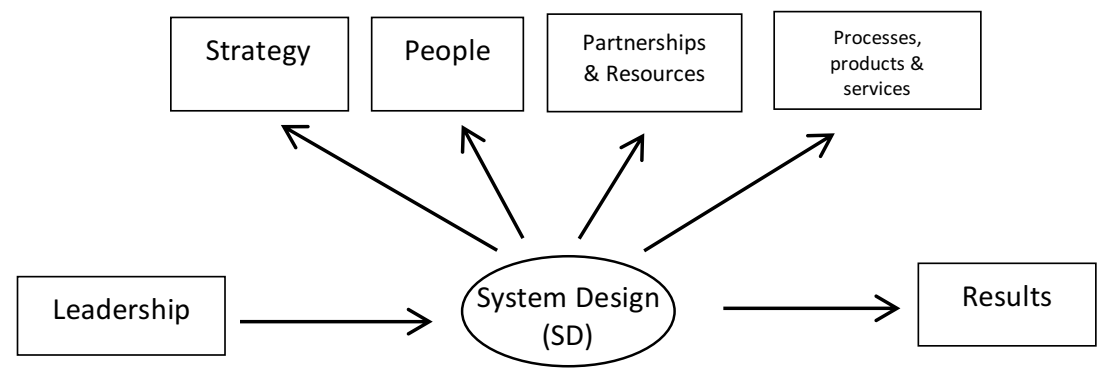


Table 1. Descriptive statistics and correlations of criteria scores $(\mathrm{N}=214)$

\begin{tabular}{|c|c|c|c|c|c|c|c|c|c|c|c|c|c|}
\hline Variable & Min. & Max. & Mean & S.D. & $\mathrm{C} 1$ & $\mathrm{C} 2$ & C3 & $\mathrm{C} 4$ & $\mathrm{C} 5$ & C6 & $\mathrm{C} 7$ & $\mathrm{C} 8$ & C9 \\
\hline $\mathrm{C} 1$ & 25.50 & 62.00 & 42.43 & 7.98 & 1 & & & & & & & & \\
\hline $\mathrm{C} 2$ & 23.75 & 66.25 & 42.84 & 8.73 & $0.865^{* *}$ & 1 & & & & & & & \\
\hline $\mathrm{C} 3$ & 25.22 & 62.25 & 40.83 & 7.76 & $0.856^{* *}$ & $0.807 * *$ & 1 & & & & & & \\
\hline C4 & 25.50 & 65.50 & 43.37 & 7.99 & $0.803 * *$ & $0.779 * *$ & $0.831 * *$ & 1 & & & & & \\
\hline C5 & 25.33 & 67.75 & 45.55 & 8.21 & $0.828 * *$ & $0.810^{* *}($ & $0.815 * *$ & $0.796^{* *}$ & 1 & & & & \\
\hline C6 & 20.00 & 68.75 & 42.85 & 9.28 & $0.699 * *$ & $0.722 * * 0$ & $0.680 * *$ & $0.688^{* *}$ & $0.724^{* *}$ & 1 & & & \\
\hline C7 & 11.25 & 60.00 & 37.56 & 9.75 & $0.676^{* *}$ & $0.638 * *$ & $0.707 * *$ & $0.542 * *$ & $0.590^{* *}$ & $0.684 * *$ & 1 & & \\
\hline C8 & 10.00 & 64.38 & 31.10 & 10.81 & $0.613^{* *}$ & $0.600 * * 0$ & $0.681 * *$ & $0.645^{* *}$ & $0.598^{* *}$ & $0.607^{* *}$ & $0.652^{* *}$ & 1 & \\
\hline $\mathrm{C} 9$ & 20.00 & 73.13 & 41.82 & 10.15 & $0.668^{* *}$ & $0.696 * *$ & $0.633^{* *}$ & $0.700^{* *}$ & $0.674^{* *}$ & $0.728 * *$ & $0.623^{* *}$ & $0.638 * *$ & 1 \\
\hline
\end{tabular}

C1: Criterion 1. Leadership; C2: Criterion 2. Strategy; C3: Criterion 3. People; C4: Criterion 4. Partnerships and Resources; C5: Criterion 5. Processes, Products and Services; C6: Criterion 6. Customer Results; C7: Criterion 7. People Results; C8: Criterion 8. Society Results; C9: Criterion 9. Business Results.

Table 2. Level of excellence and size-observed frequencies

\begin{tabular}{ccccc}
\hline & 5-stars & 4-stars & 3-stars & Total \\
\hline SMEs & 14 & 67 & 50 & 131 \\
Large & 25 & 34 & 24 & 83 \\
Total & 39 & 101 & 74 & 214 \\
\hline
\end{tabular}


Table 3. Contingency analysis of the level of EFQM criteria and sub-criteria

\begin{tabular}{|c|c|c|c|}
\hline \multirow{2}{*}{\multicolumn{2}{|c|}{ Definition of the criteria }} & \multicolumn{2}{|c|}{ Mean } \\
\hline & & \multirow{2}{*}{$\begin{array}{ll}\text { SMEs } \\
41.66 \\
\end{array}$} & \multirow{2}{*}{$\begin{array}{ll}\text { Large } \\
43.64 \\
\end{array}$} \\
\hline C1 & Leadership & & \\
\hline $\mathrm{C2}$ & Strategy & 41.93 & 44.29 \\
\hline $\mathrm{C3}$ & \begin{tabular}{|l|} 
People \\
\end{tabular} & 39.72 & 42.59* \\
\hline $\mathrm{C} 4$ & Partnerships \& Resources & 41.28 & $46.67 * *$ \\
\hline C5 & Processes, products and services & 44.10 & $47.85 * *$ \\
\hline C6 & Customer Results & 41.53 & $44.92 *$ \\
\hline C7 & People Results & 37.45 & 37.72 \\
\hline $\mathrm{C8}$ & Society Results & 29.02 & $34.39 * *$ \\
\hline \multirow[t]{2}{*}{ C9 } & Business Results & 39.65 & $45.25 * *$ \\
\hline & Definition of the sub-criteria & & \\
\hline SUB1a & Leaders develop the Mission, Vision, Values and ethics and act as role models & 43,90 & 45,29 \\
\hline SUB1b & $\begin{array}{l}\text { Leaders define, monitor, review and drive the improvement of the organization's } \\
\text { management system and performance }\end{array}$ & 43,41 & 45,25 \\
\hline SUB1c & Leaders engage with external stakeholders & 40,93 & 42,81 \\
\hline SUB1d & Leaders reinforce a culture of excellence with the organization's people & 40,96 & 42,62 \\
\hline SUB1e & Leaders ensure that organization is flexible and manages change effectively & 39,26 & 41,91* \\
\hline SUB2a & $\begin{array}{l}\text { Strategy is based on understanding the needs and expectations of both stakeholders } \\
\text { and the external environment }\end{array}$ & 42,16 & 44,34 \\
\hline SUB2b & Strategy is based on understanding internal performance and capabilities & 41,56 & 44,73* \\
\hline SUB2c & Strategy and supporting policies are developed, reviewed and updated & 42,68 & 44,82 \\
\hline SUB2d & Strategy and supporting policies are communicated, implemented and monitored & 41,47 & 43,21 \\
\hline SUB3a & People plans support the organization's strategy & 39,94 & $42,66 *$ \\
\hline SUB3b & People's knowledge and capabilities are developed & 41,35 & $45,06 * *$ \\
\hline SUB3c & People are aligned, involved and empowered & 39,81 & 41,70 \\
\hline SUB3d & People communicate effectively throughout the organization & 40,27 & 42,60 \\
\hline SUB3e & People are rewarded, recognized and cared for & 37,17 & $40,87 * *$ \\
\hline SUB4a & Partners and suppliers are managed for sustainable benefit & $\mathbf{4 0 , 2 4}$ & $43,71 * *$ \\
\hline SUB4b & Finances are managed to secure sustained success & 43,17 & $50,65 * *$ \\
\hline SUB4c & $\begin{array}{l}\text { Buildings, equipment, materials and natural resources are managed in a sustainable } \\
\text { way }\end{array}$ & 40,11 & $47,23 * *$ \\
\hline SUB4d & Technology is managed to support the delivery of strategy & 42,97 & $48,20 * *$ \\
\hline SUB4e & $\begin{array}{l}\text { Information and knowledge are managed to support effective decision making and } \\
\text { to build the organization's capability }\end{array}$ & 40,07 & $43,55^{* *}$ \\
\hline SUB5a & Processes are designed and managed to optimize stakeholder value & 48,57 & 50,00 \\
\hline SUB5b & Products and Services are developed to create optimum value for customers & 43,08 & $46,92 * *$ \\
\hline SUB5c & Products and Services are effectively promoted and marketed & 42,02 & $45,92 * *$ \\
\hline SUB5d & Products and Services are produced, delivered and managed & 44,13 & $49,12 * *$ \\
\hline SUB5e & Customer relationships are managed and enhanced & 42,89 & $47,31 * *$ \\
\hline SUB6a & Analysis of customer's perceptions of the organization & 42,56 & $45,90 *$ \\
\hline SUB6b & $\begin{array}{l}\text { Analysis of performance indicators: internal measures used by the organization in } \\
\text { order to monitor, understand, predict and improve performance of the } \\
\text { organization's external customers }\end{array}$ & 38,72 & $42,08^{*}$ \\
\hline SUB7a & Analysis of people's perceptions of the organization & 38,35 & 37,97 \\
\hline SUB7b & $\begin{array}{l}\text { Analysis of performance indicators: internal measures used by the organization in } \\
\text { order to monitor, understand, predict and improve the performance of the } \\
\text { organization's people }\end{array}$ & 34,74 & 37,17 \\
\hline SUB8a & Analysis of society's perceptions of the organization & 27,79 & $32,71 * *$ \\
\hline SUB8b & $\begin{array}{l}\text { Analysis of performance indicators: internal measures used by the organization in } \\
\text { order to monitor, understand, predict and improve performance of the } \\
\text { organization's relevant society stakeholders }\end{array}$ & 30,06 & $35,97 * *$ \\
\hline SUB9a & $\begin{array}{l}\text { Key strategic outcomes: key financial and non-financial outcomes which } \\
\text { demonstrate the success of the organization's deployment of their strategy }\end{array}$ & 40,67 & $46,15 * *$ \\
\hline SUB9b & $\begin{array}{l}\text { Key performance indicators: key financial and non-financial indicators that are } \\
\text { used to measure the organization's operational performance }\end{array}$ & 38,56 & $44,34 * *$ \\
\hline
\end{tabular}

Note: $(*) p<0.05 ;(* *) p<0.01$ 
Table 4. Standardized Solutions: whole sample and multisample models of criteria

\begin{tabular}{|c|c|c|c|c|c|c|}
\hline \multirow[b]{3}{*}{ Effect } & \multirow{2}{*}{\multicolumn{2}{|c|}{ Whole Sample }} & \multicolumn{4}{|c|}{ Multisample Analysis } \\
\hline & & & \multicolumn{2}{|c|}{ SMES } & \multicolumn{2}{|c|}{ Large } \\
\hline & $\begin{array}{l}\text { Parameter } \\
\text { estimates }\end{array}$ & $\mathbf{R}^{2}$ & $\begin{array}{l}\text { Parameter } \\
\text { estimates }\end{array}$ & $\mathbf{R}^{2}$ & $\begin{array}{l}\text { Parameter } \\
\text { estimates }\end{array}$ & $\mathbf{R}^{2}$ \\
\hline \multicolumn{7}{|l|}{$\begin{array}{l}\text { Item-Factor } \\
\text { Loadings }\end{array}$} \\
\hline $\mathrm{SD} \rightarrow$ Strategy & $0.904 * *$ & 0.818 & $0.891 * *$ & 0.795 & $0.921 * *$ & 0.848 \\
\hline SD $\rightarrow$ People & $0.882 * *$ & 0.841 & $0.879 * *$ & 0.773 & $0.938 * *$ & 0.879 \\
\hline $\begin{array}{l}\text { SD } \rightarrow \text { Partnerships \& } \\
\text { Resources }\end{array}$ & $0.894 * *$ & 0.778 & $0.809 * *$ & 0.654 & $0.943 * *$ & 0.889 \\
\hline $\begin{array}{l}\mathrm{SD} \rightarrow \text { Processes, } \\
\text { products and services }\end{array}$ & $0.894 * *$ & 0.799 & $0.877 * *$ & 0.770 & $0.907 * *$ & 0.823 \\
\hline \multicolumn{7}{|l|}{ Structural Effects } \\
\hline Leadership $\rightarrow$ SD & $0.929 * *$ & 0.864 & $0.903 * *$ & 0.816 & $0.964 * *$ & 0.930 \\
\hline $\mathrm{SD} \rightarrow$ Results & $0.849 * *$ & 0.720 & $0.741 * *$ & 0.549 & $0.928 * *$ & 0.862 \\
\hline $\begin{array}{l}\text { Multisample } \\
\text { Global Fit }\end{array}$ & & & Satorra-B & $\begin{array}{r}\text { tler } \chi^{2} \\
p= \\
\text { B-NNF } \\
\text { RMSEA }\end{array}$ & $\begin{array}{l}=28.6243 \\
0.07 \\
I=0.975 \\
=0.069\end{array}$ & d.f.) \\
\hline
\end{tabular}

Note: Standardized regression coefficients; $(* *) p<0.01$

BB-NNFI: Bentler-Bonett Non-normed fit index

RMSEA: Root Mean Square Error of Approximation 